\title{
Characterization of aramid based activated carbon fibres by adsorption and immersion techniques
}

(Carbon 14, 1376-1380, 2002)

\author{
S. Villar-Rodil ${ }^{\mathrm{a}}$,, R. Denoyel ${ }^{\mathrm{a}}$, J. Rouquerol ${ }^{\mathrm{a}}$, A. Martínez-Alonso ${ }^{\mathrm{b}}$ and J.M.D. Tascón ${ }^{\mathrm{b}}$ \\ ${ }^{a}$ MADIREL (CNRS-Université de Provence), Site CTM, 26 rue du 14lème RIA, \\ 13331 Marseille, Cedex 3, France. \\ ${ }^{\mathrm{b}}$ Instituto Nacional del Carbón, CSIC, Apartado 73, 33080 Oviedo, Spain.
}

In recent years, there have been a number of studies on the textural properties of aramid-based activated carbon fibres (ACFs). Freeman et al. [1,2] first used aramid fibres as feedstock materials expecting to obtain ACFs with distinctive adsorbent properties as a result of the high cristallinity of the precursor. Stoeckli et al [3] examined the pore structure of steam activated carbon fibres coming from Nomex and Kevlar through adsorption of $\mathrm{CH}_{2} \mathrm{Cl}_{2}$ and $\mathrm{N}_{2} \mathrm{O}$ vapours and immersion calorimetry into liquids of different molecular sizes. In one of the authors' laboratories, Kevlar pulp and Nomex have been activated with $\mathrm{CO}_{2}$ and studied by $\mathrm{N}_{2}$ and $\mathrm{CO}_{2}$ adsorption and SEM [4-7]. The general conclusion of all these studies is that aramid (especially Nomex) based ACFs have pore size distributions (PSDs) narrower than those of conventional activated carbons and even than those of ACFs coming from less ordered polymeric precursors [8]. This narrow PSD suggests a possible application of these materials in gas separations.

In this context, a detailed study on the textural properties of these ACFs focusing on the determination of their PSD can be useful to predict if they could be used as molecular sieves either directly or after modification of their textural characteristics with further treatments. With this aim, in this work, $\mathrm{N}_{2}(77 \mathrm{~K})$ and $\mathrm{CO}_{2}(273 \mathrm{~K})$ adsorption 
isotherms have been measured on a series of steam-activated Nomex-based ACFs trying to elucidate PSDs in an indirect way through different calculation methods. Moreover, immersion calorimetry using adsorptive molecules of different size as molecular probes has been used to obtain a direct measurement of the amounts of pores of different sizes.

The starting material was commercially available Nomex [poly ( $m$-phenylene isophtalamide) in a variety known as Crystalline Nomex (T450 2.2 dtex.). All treatments were carried out in a tubular quartz reactor. Batches of about $10 \mathrm{~g}$ of as received Nomex were pyrolysed in argon (flow rate: $50 \mathrm{~cm}^{3} \mathrm{~min}^{-1}$ ) up to $1073 \mathrm{~K}$ (heating rate: $10 \mathrm{~K} \mathrm{~min}^{-1}$ ) and then cooled down to $1053 \mathrm{~K}$ and activated with a steam/argon mixture $\left(720 \mathrm{~cm}^{-3} \mathrm{~min}^{-1}\right.$ $/ 50 \mathrm{~cm}^{-3} \mathrm{~min}^{-1}$ ) during certain periods of time to attain different burn-offs (BO), namely, 0 , $10,21,42$ and $63 \%$.

Adsorption isotherms of $\mathrm{N}_{2}(77 \mathrm{~K})$ and $\mathrm{CO}_{2}(273 \mathrm{~K})$ were assessed in a Micromeritics ASAP 2000 and a Quantachrome NOVA 1200 volumetric adsorption analyser, respectively. Samples were outgassed overnight under vacuum at $523 \mathrm{~K}$ prior to every adsorption experiment. The densities employed for adsorbed $\mathrm{N}_{2}(77 \mathrm{~K})$ and $\mathrm{CO}_{2}$ $(273 \mathrm{~K})$ were respectively 0.813 and $1.182 \mathrm{~g} \mathrm{~cm}^{-3}$ [9]. BET surface areas, $S_{B E T}$, were obtained by the standard BET method in the relative pressure range from $10^{-6}$ to 0.1 [10]. The value used for the affinity coefficient for $\mathrm{CO}_{2}$ in Dubinin-Radushkevich (DR) calculations is 0.42 . PSD from the $\mathrm{N}_{2}$ and $\mathrm{CO}_{2}$ adsorption data were obtained through the application of non local density functional theory (NLDFT) procedure [11] using softwares provided by Micromeritics Instrument Corporation $\left(\mathrm{N}_{2}\right)$ and Quantachrome $\left(\mathrm{CO}_{2}\right)$ [12].

The heats of immersion of the samples into liquids with different minimal molecular dimensions such as $\mathrm{CH}_{2} \mathrm{Cl}_{2}(0.33 \mathrm{~nm}), \mathrm{C}_{6} \mathrm{H}_{6}(0.37 \mathrm{~nm})$ and $\mathrm{C}_{6} \mathrm{H}_{12}(0.48 \mathrm{~nm})$ were determined at $298 \mathrm{~K}$ with a Tian-Calvet differential microcalorimeter (Setaram, Model C80D). The samples ( 0.1 g) were outgassed overnight under vacuum at $523 \mathrm{~K}$. 
The experimental procedure to determine enthalpies of immersion has been described elsewhere [13]. The accessible surface areas of the samples from immersion calorimetry data were determined following the method proposed by Denoyel et al. [14], using as a reference the areal enthalpies of immersion of Vulcan $3\left(S_{B E T}=82 \mathrm{~m}^{2} \mathrm{~g}^{-1}\right)$.

The $\mathrm{N}_{2}$ adsorption isotherms obtained for the samples under study are shown in Fig. 1. The adsorption isotherm on the simply pyrolysed sample is not included because its porosity is too narrow to be accessible to $\mathrm{N}_{2}$ at $77 \mathrm{~K}$. All isotherms belong to type I according to the IUPAC classification [15], although distinctions can be established among them according to the opening of their knee as the BO increases, pointing to a certain widening in the microporosity barely extending to mesoporosity in the most activated sample, as shown by the appearance of a very narrow hysteresis loop in its isotherm. From the comparison of the textural properties of Nomex-derived materials with ACFs coming from other precursors in literature [16-18], the usual widening of the porosity at high BO when activating with steam, leading to pronounced slopes and hysteresis loops is not found here. This is remarkable, most of all, taking into account the "drastic" experimental conditions (high steam concentration) used in the steam activation carried out in this work.

$\mathrm{CO}_{2}$ adsorption isotherms (not shown) for the series evidence that $\mathrm{CO}_{2}$ uptake increases with $\mathrm{BO}$ degree in the earliest stages of activation throughout all the relative pressure range covered while a decrease in the uptake at low pressures is observed for the further activated samples, reflecting the disappearance of some of the narrowest microporosity.

Table 1 shows different parameters deduced from $\mathrm{N}_{2}$ and $\mathrm{CO}_{2}$ adsorption: BET surface areas $\left(S_{B E T}\right)$ and total pore volumes $\left(V_{p(N 2)}\right)$ derived from $\mathrm{N}_{2}$ adsorption as well as textural parameters deduced from the application of the DR equation to $\mathrm{N}_{2}$ or $\mathrm{CO}_{2}$ adsorption data such as micropore volumes $\left(V_{\mu p(D R, N 2)}\right.$ and $V_{\mu p(D R, C O 2)}$, respectively) and 


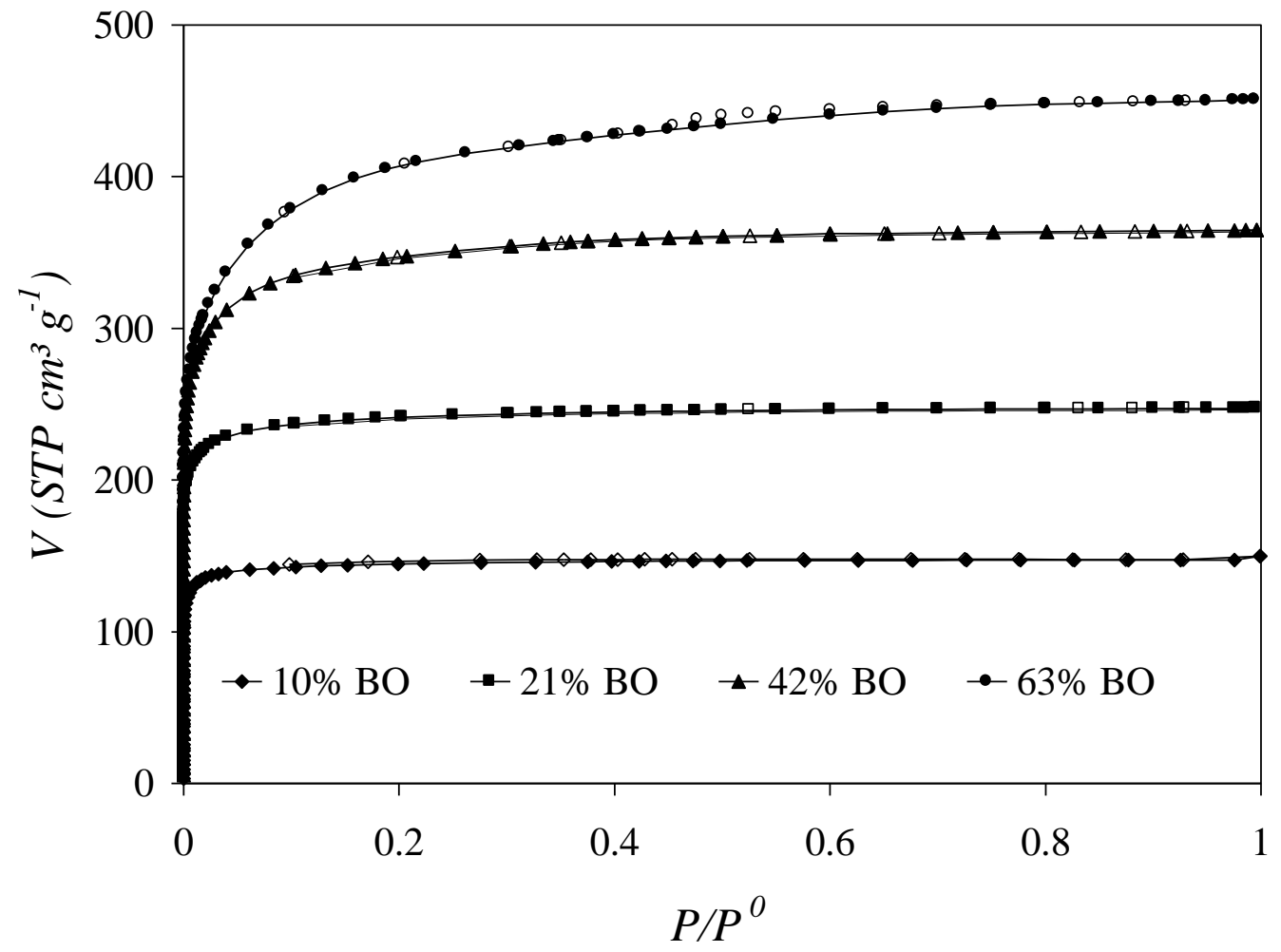

Figure 1. Adsorption-desorption $\mathrm{N}_{2}$ isotherms $(77 \mathrm{~K})$ for the samples under study. Filled symbols, adsorption; empty symbols, desorption.

Table 1. Textural parameters derived from $\mathrm{N}_{2}(77 \mathrm{~K})$ and $\mathrm{CO}_{2}(273 \mathrm{~K})$ adsorption.

\begin{tabular}{cccccc}
\hline$\%$ BO & $\begin{array}{c}S_{B E T} \\
\left(\mathrm{~m}^{2} \mathrm{~g}^{-1}\right)\end{array}$ & $\begin{array}{c}V_{p(N 2)} \\
\left(\mathrm{cm}^{3} \mathrm{~g}^{-1}\right)\end{array}$ & $\begin{array}{c}V_{\mu p(D R, N 2)} \\
\left(\mathrm{cm}^{3} \mathrm{~g}^{-1}\right)\end{array}$ & $\begin{array}{c}V_{\mu p(D R, C O 2)} \\
\left(\mathrm{cm}^{3} \mathrm{~g}^{-1}\right)\end{array}$ & $\begin{array}{c}L_{(D R, C O 2)} \\
(\mathrm{nm})\end{array}$ \\
\hline 0 & - & - & - & 0.16 & 0.93 \\
10 & 560 & 0.23 & 0.23 & 0.22 & 1.01 \\
21 & 936 & 0.38 & 0.38 & 0.26 & 1.25 \\
42 & 1329 & 0.56 & 0.56 & 0.29 & 1.12 \\
63 & 1580 & 0.69 & 0.68 & 0.38 & 1.33 \\
\hline
\end{tabular}


mean pore widths $\left(L_{(D R, C O 2)}\right)$. The very low relative pressures from which BET plots show linearity $\left(\sim 10^{-6}-10^{-5}\right)$ for all the samples are already an indication of the highly microporous nature of their texture [19]. This is also confirmed by the fact that $V_{p(N 2)}$ and $V_{\mu p(D R, N 2)}$ are coincident with each other except for a slight difference found for the $63 \%$ BO sample. This indicates that porosity develops mainly through the creation of new micropores. $S_{B E T}, V_{p(N 2)}, V_{\mu p(D R, N 2)}$ and $V_{\mu p(D R, C O 2)}$ increase with increasing BO degree over the range covered by this series. In comparing $V_{\mu p(D R, N 2)}$ and $V_{\mu p(D R, C O 2) \text {, while for the }}$ lower BO degrees the $V_{\square p(D R, C O 2)}$ are either greater (0\% BO) or comparable (10\% $\mathrm{BO}$ ) to $V_{p(N 2)}$, they become comparatively lower for the higher ones $(21,42,63 \%)$. These situations arise from the different relative importance of the dissimilar porosity ranges covered by the two adsorbates [12], which are thought to be $0.3 \mathrm{~nm}$ to about $1.4 \mathrm{~nm}$ [21] for $\mathrm{CO}_{2}$ adsorption $(273 \mathrm{~K})$ and $0.4 \mathrm{~nm}$ to about $50 \mathrm{~nm}$ for $\mathrm{N}_{2}(77 \mathrm{~K})$. Thus, the pyrolysed sample would have porosity restricted to the pore width interval $0.3-0.4 \mathrm{~nm}$. For the rest of the samples, a further development of porosity beyond the upper limit of $1.4 \mathrm{~nm}$ covered by $\mathrm{CO}_{2}$ adsorption takes place. $\left.L_{(D R}, C O 2\right)$ rather increases with increasing $\mathrm{BO}$ showing values around $1 \mathrm{~nm}$. Comparing with previous results obtained in one of the authors' laboratories for samples activated with $\mathrm{CO}_{2}[5,6]$, steam-activated samples show greater $S_{B E T}$ and $V_{p(N 2)}$ at similar BO values indicating a further development of porosity (namely microporosity, as $V_{p(N 2)}$ and $V_{\mu p}(D R, N 2)$ continue to be coincident with each other as BO increases). However, $V_{\mu p(D R, C O 2)}$ is slightly lower for steam activated samples than for $\mathrm{CO}_{2}$ activated ones, indicating that the narrowest porosity is more retained in the latter. Nevertheless, the differences between the series prepared in those different ways are not perhaps so drastic as with other precursors [16-18], most of all when comparing $V_{\mu p}(D R$, ${ }_{C O 2)}$ or $L_{(D R, C O 2)}$. Therefore, the precursor material seems to have a marked effect on the 
porosity of the final ACFs, limiting the widening of porosity and the differences between samples resulting from activation with different activating gases.

PSDs derived from $\mathrm{N}_{2}$ and $\mathrm{CO}_{2}$ adsorption isotherms through NLDFT calculations are shown in Fig. 2. In the PSDs derived from $\mathrm{N}_{2}$ adsorption all samples present maxima around $0.6 \mathrm{~nm}$, the largest pore size being 1.6, 2.0, 3.2 and $7.0 \mathrm{~nm}$, respectively, for the samples arranged in increasing BO sequence. The PSDs reflect a widening in the micropore size distribution with increasing $\mathrm{BO}$, which takes place in a restricted pore size range mainly below $2.0 \mathrm{~nm}$, i.e., in the microporosity range, for all the samples except the one activated at $63 \% \mathrm{BO}$. As concerns the PSDs from $\mathrm{CO}_{2}$ adsorption data, widening of the pores is also appreciated in the porosity range covered, as one has PSDs with maxima around 0.35 and $0.50 \mathrm{~nm}(0 \% \mathrm{BO}), 0.50-0.60 \mathrm{~nm}(10 \% \mathrm{BO}), 0.60 \mathrm{~nm}(21 \%$ and $42 \% \mathrm{BO})$ and $0.82 \mathrm{~nm}(63 \% \mathrm{BO})$. Both PSDs rather consistently show maxima around 0.5-0.6 nm for all the samples but that activated to $63 \%$ BO. Moreover, if pore volumes calculated from both PSDs (not given) are compared for the same samples for pore widths under approximately $0.7 \mathrm{~nm}$, they result to be similar to each other. Slight differences arise from the fact that the two adsorptives have different accessibilities to the micropore system and so the lower pore width reached is different. Comparing with the $L_{(D R, C O 2)}$ values resulting from the DR method, PSDs are shifted to lower pore sizes.

Table 2 shows the experimental enthalpies of immersion of all the samples but the one activated to the highest $\mathrm{BO}$ in the different studied organic liquids as well as the calculated accessible surface areas. That sample (63\% BO) has been useful to set an upper limit for the development of exclusively microporosity through activation, but it has been excluded from this further analysis because it is not interesting in the context of its possible application as a molecular sieve carbon. The values for the experimental enthalpies of 

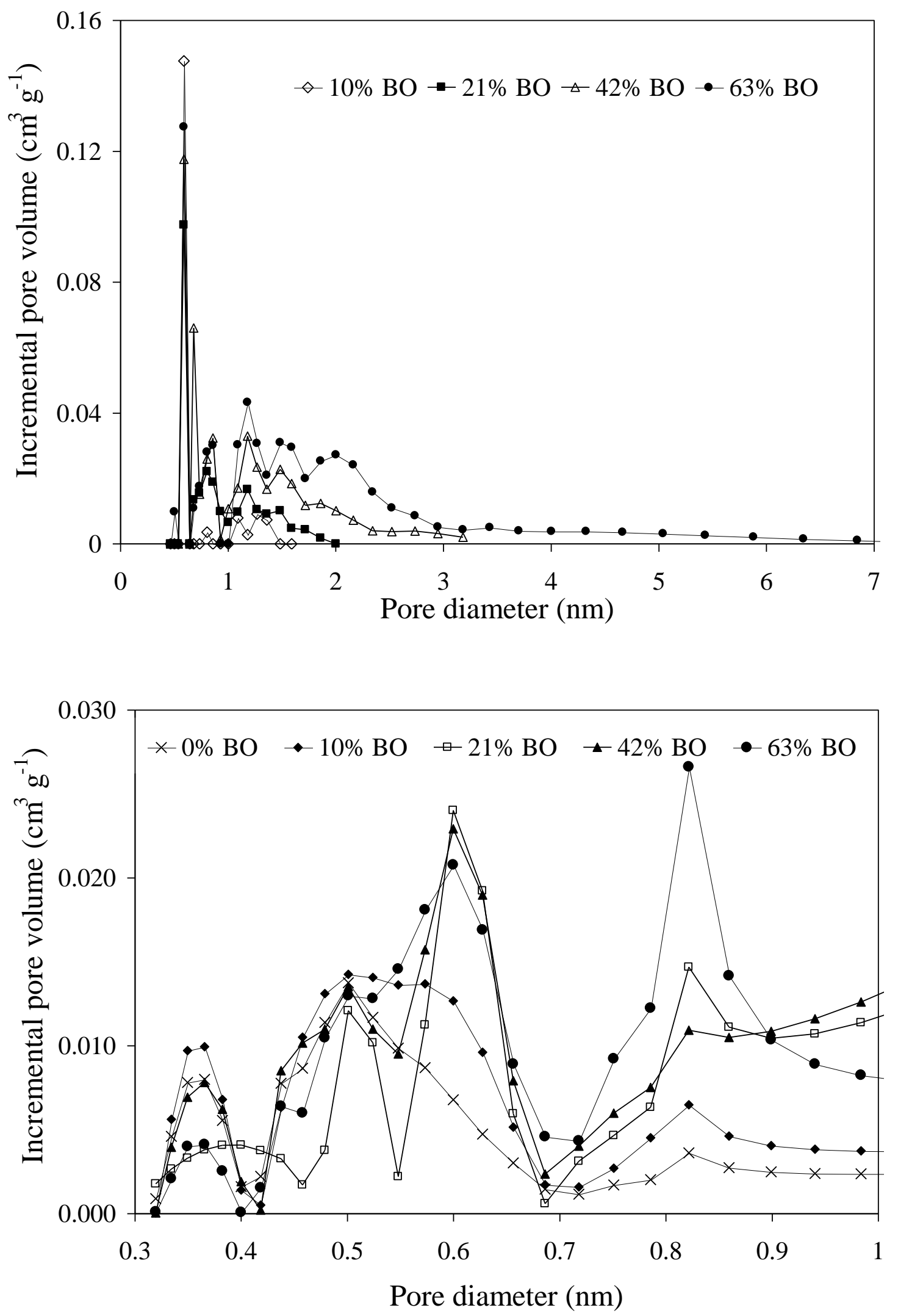

Figure 2. PSDs obtained from the $\mathrm{N}_{2}$ (a) and $\mathrm{CO}_{2}$ (b) adsorption isotherms through application of the NLDFT method. 
immersion are consistent with those previously obtained by Stoeckli et al. [3] for samples with similar BOs, irrespective of the different activation conditions used to reach them.

Table 2. Experimental enthalpies of immersion at $298 \mathrm{~K}$ into different liquids and surface areas derived from them and from $\mathrm{N}_{2}$ adsorption at $77 \mathrm{~K}$.

\begin{tabular}{|c|ccc|ccc|c|}
\hline \multirow{2}{*}{$\%$ BO } & \multicolumn{3}{|c|}{$-\Delta H_{\text {imm }}\left(\mathrm{J} \mathrm{g}^{-1}\right)$} & \multicolumn{3}{c|}{ Surface areas $\left(\mathrm{m}^{2} \mathrm{~g}^{-1}\right)$} & \multirow{2}{*}{$S_{B E T}\left(\mathrm{~m}^{2} \mathrm{~g}^{-1}\right)$} \\
\cline { 2 - 6 } & $\mathrm{CH}_{2} \mathrm{Cl}_{2}$ & $\mathrm{C}_{6} \mathrm{H}_{6}$ & $\mathrm{C}_{6} \mathrm{H}_{12}$ & $\mathrm{CH}_{2} \mathrm{Cl}_{2}$ & $\mathrm{C}_{6} \mathrm{H}_{6}$ & $\mathrm{C}_{6} \mathrm{H}_{12}$ & \\
\hline 0 & 45.3 & 11.0 & 10.0 & 338 & 100 & 96 & $-^{\mathrm{a}}$ \\
10 & 92.1 & 65.9 & 47.6 & 687 & 600 & 460 & 560 \\
21 & 123.1 & 122.4 & 81.6 & 918 & 1116 & 787 & 936 \\
42 & 138.1 & 146.7 & 107.6 & 1029 & 1337 & 1038 & 1329 \\
\hline
\end{tabular}

${ }^{a}$ Only geometrical surface

The low activated samples (0 and $10 \%$ BO) show surface areas accessible to $\mathrm{CH}_{2} \mathrm{Cl}_{2}$ higher than those accessible to $\mathrm{C}_{6} \mathrm{H}_{6}$. However, the rest of the samples show the opposite trend. The occurrence of a transformation of the texture leading to a pore network mainly composed of slit-shaped pores, favouring the access of planar molecules as $\mathrm{C}_{6} \mathrm{H}_{6}$ is a possible explanation for this effect. In fact, typical activated carbons are supposed to possess a porous network of that kind, but the samples activated to low BO might depart from this picture, with other pore shapes, restricting the accessibility of $\mathrm{C}_{6} \mathrm{H}_{6}$ molecules. Surface areas accessible to $\mathrm{C}_{6} \mathrm{H}_{6}$ are systematically higher than the corresponding BET $\left(\mathrm{N}_{2}\right)$ surface areas. The minimal dimensions of $\mathrm{N}_{2}(0.36 \mathrm{~nm})$ and $\mathrm{C}_{6} \mathrm{H}_{6}(0.37 \mathrm{~nm})$ being nearly the same, both molecules should have access to similar microporosity ranges. It has been asserted [14] that this difference arises from the underestimation of the actual surface of microporous carbons having pores with widths similar to one adsorbate molecule by the calculation of BET surface area considering that one molecule is in contact with only one planar surface. Instead of that, in the immersion method, the interaction of the molecule 
with both walls of the pore is taken into account leading to higher, more realistic values. Therefore, the largest differences between surface areas derived from $\mathrm{N}_{2}$ and $\mathrm{C}_{6} \mathrm{H}_{6}$ adsorption appear in the samples with the narrowest porosities accessible to both molecules, being hardly noticeable in the sample activated to $42 \% \mathrm{BO}$. For the next probe molecule, cyclohexane, the values for accessible surface areas are lower than BET surface areas for all the samples except the pyrolysed one. The different sizes of $\mathrm{N}_{2}(0.36 \mathrm{~nm})$ and $\mathrm{C}_{6} \mathrm{H}_{12}(0.48 \mathrm{~nm})$ molecules justify the differences as the bigger molecules will access a smaller fraction of microporosity on the samples. However, for the pyrolysed sample, the surface area accessible to cyclohexane is higher than the BET surface area (assuming this to be the geometrical one). Similar effects have been explained as a consequence of a possible wrong value for $\mathrm{N}_{2}$ density [24].

In conclusion, the use of Nomex fibres as a precursor yields ACFs with rather narrow PSDs irrespective of the activation conditions (type and concentration of activating agent, etc.) used, in contrast with what happens with other precursors [16-18]. From the deduced PSDs and the observed molecular sieve effects, the pyrolysed sample could be in principle a good molecular sieve, al least from the point of view of selectivity. The usual drawback against the use of simply pyrolysed carbonaceous materials as molecular sieves is their low adsorption capacity. However, this is not the case here, as the micropore volume of the sample $\left(V_{\mu p(D R, C O 2)}=0.16 \mathrm{~cm}^{3} \mathrm{~g}^{-1}\right)$ is well inside the range of those exhibited by commercial and non-commercial carbon molecular sieves in literature $[25,26]$. Moreover, the densities used in literature for $\mathrm{CO}_{2}$ adsorbed at $273 \mathrm{~K}$ are typically lower than the one used in this work and consequently the values for micropore volumes are "enlarged" in relation with ours. As for the activated samples, their rather small and uniform pore sizes make them promising as CMS precursor through carbon chemical vapour deposition [27]. However, the sample activated to the highest BO shows a small 
amount of mesopores that makes doubtful its possible application even as precursor of carbon molecular sieves [27]. Moreover, such a high BO is not admissible from a practical point of view even in a conventional activated carbon.

\section{Acknowledgements}

The authors wish to thank their colleagues Javier Fernández and Celina Blanco (DuPont Asturias) for providing the Nomex sample. Financial support from CICYT (Project 1FD1997-1915) and MCYT (Project BQU2001-2936-C02-02) is gratefully acknowledged.

\section{References}

[1] Freeman JJ, Tomlinson JB, Sing KSW, Theocharis CR. Adsorption of nitrogen and water vapour by activated Kevlar® chars. Carbon 1993; 6:865-869.

[2] Freeman JJ, Tomlinson JB, Sing KSW, Theocharis CR. Adsorption of nitrogen and water vapour by activated Nomex ${ }^{\circledR}$ chars. Carbon 1995; 33:795-799.

[3] Stoeckli F, Centeno TA, Fuertes AB, Muñiz J. Porous structure of polyarylamide-based activated carbon fibres. Carbon 1996; 34:1201-1206.

[4] Martínez-Alonso A, Jamond M, Montes-Morán MA, Tascón JMD. Microporous texture of activated carbon fibers prepared from aramid fiber pulp. Microporous Materials $1997 ; 11: 303-311$.

[5] Blanco López MC, Martínez-Alonso A, Tascón JMD. Microporous texture of activated carbon fibres prepared from Nomex aramid fibres. Microporous and Mesoporous Materials $2000 ; 34: 171-179$.

[6] Blanco López MC, Martínez-Alonso A, Tascón JMD. $\mathrm{N}_{2}$ and $\mathrm{CO}_{2}$ adsorption on activated carbon fibres prepared from Nomex chars. Carbon 2000; 38:1173-1182.

[7] Blanco López M., Villar-Rodil SM, Martínez-Alonso A, Tascón JMD, Effect of some 
precursor characteristics on the porous texture of activated carbon fibres prepared from Nomex aramid fibres. Microporous and Mesoporous Materials 2000; 41(1-3):319-321.

[8] Matsumoto A, Zhao J, Tsutsumi K. Adsorption behavior of hydrocarbons on slitshaped micropores. Langmuir 1997; 13:496-501.

[9] Cascarini de Torre LE, Bottani EJ, Steele WA, Amorphous carbons: surface structure and adsorptive properties. Langmuir 1996; 12:5399-5406.

[10] Ryu Z, Zheng J, Wang M, Zhang B. Nitrogen adsorption studies of PAN-based activated carbon fibers prepared by different activation methods. J. Colloid Interface Sci. 2000; 230:312-319.

[11] Olivier JP, Conkin WPB, Szombathely MV. In Rouquerol J, Rodríguez-Reinoso F, Sing KSW, Unger KK, editors. Characterization of Porous Solids III, Amsterdam: Elsevier 1994; 81-89.

[12] Vishnyakov A, Ravikovitch PI, Neinmark AV. Molecular level models for $\mathrm{CO}_{2}$ sorption in nanopores. Langmuir 1999; 15:8736-8742.

[13] Partyka S, Rouquerol F, Rouquerol J. Calorimetric determination of surface area: Possibilities of a modified Harkins and Jura procedure. J. Colloid Interface Sci. 1979; $68: 21-31$

[14] Denoyel R, Fernandez-Colinas J, Grillet Y, Rouquerol J. Assesment of the surface area of charcoals from immersion calorimetry and nitrogen adsorption data. Langmuir $1993 ; 9: 515-518$.

[15] Sing KSW, Everett DH, Haul RAW, Moscou L, Pieriotti RA, Rouquerol J, Siemieniewska T. Reporting physisorption data for gas/solid systems with special reference to the determination of surface area and porosity. Pure Appl. Chem. 1985; 57:603-919. 
[16] Ryu SK, Jin H, Gondy D, Pusset N, Ehrburger P. Activation of carbon fibres by steam and carbon dioxide. Carbon 1993; 31:841-842.

[17] Alcañiz-Monge J, Cazorla-Amorós D., Linares-Solano A, Yoshida S, Oya A. Effect of activating gas on tensile strength and pore structure on pitch-based carbon fibres. Carbon $1994 ; 32: 1277-1283$.

[18] Rodríguez-Reinoso F, Molina-Sabio M., González MT. The use of steam and $\mathrm{CO}_{2}$ as activating agents in the preparation of activated carbons. Carbon 1994; 33:15-23.

[19] Rouquerol F, Rouquerol J, Imelik B, Bull. Soc. Chim. Fr. 1964; 635.

[20] Garrido J, Linares-Solano A, Martín-Martínez JM, Molina-Sabio M, RodríguezReinoso F, Torregrosa R. Use of $\mathrm{N}_{2}$ vs. $\mathrm{CO}_{2}$ in the characterization of activated carbons. Langmuir 1987; 3:76-81.

[21] Vishnyakov A, Ravikovitch PI, Neinmark AV. Molecular level models for $\mathrm{CO}_{2}$ sorption in nanopores. Langmuir 1999; 15:8736-8742.

[22] Olivier JP. Improving the models used for calculating the size distribution of the micropore volume of activated carbons from adsorption data. Carbon 1998; 36:469-1472. [23] Sing KSW. Adsorption methods for the characterization of porous materials. Adv. Colloid Interface Sci. 1998; 76-77:3-11.

[24] Carrott PJM, Ribeiro Carrott MMl, Cansado IPP. Application of the $\square_{\mathrm{S}}$ method for analysing benzene, dichloromethane and methanol isotherms determined on molecular sieve and superactivated carbons. In Unger et al., editors. Studies in Surface Science and Catalysis 128, 323-331. Amsterdam: Elsevier, 2000.

[25] De la Casa-Lillo MA, Alcañiz-Monge E, Raymundo-Piñero E, Cazorla-Amorós D, Linares-Solano A. Molecular sieve properties of general-purpose carbon fibres. Carbon $1998 ; 36: 1353-1360$. 
[26] Reid CR, O'Koye IP, Thomas KM. Adsorption of gases on carbon molecular sieves used for air separation. Spherical adsorptives as probes for kinetic selectivity. Langmuir $1998 ; 14: 2415-2425$.

[27] Freitas MMA, Figueiredo JL. Preparation of carbon molecular sieves for gas separations by modification of pore sizes of activated carbons. Fuel 2001; 80:1-6. 